\title{
Prevalence and Incidence of Phacidiopycnis Rot in d'Anjou Pears in Washington State
}

\author{
C. L. Xiao and R. J. Boal, Department of Plant Pathology, Washington State University, Tree Fruit Research and \\ Extension Center, 1100 N. Western Avenue, Wenatchee 98801
}

\begin{abstract}
Xiao, C. L., and Boal, R. J. 2004. Prevalence and incidence of Phacidiopycnis rot in d'Anjou pears in Washington State. Plant Dis. 88:413-418.

Phacidiopycnis rot, caused by Phacidiopycnis piri, is a newly recognized postharvest disease in pear fruit (Pyrus communis cv. d'Anjou) in the United States. To determine the prevalence and incidence of this disease, decayed fruit were sampled during packing and repacking operations from four packinghouses in 2001 and 2002. During March to May (repacking) in 2001, Phacidiopycnis rot was found in packed fruit that were stored in cardboard boxes from 22 of 26 grower lots (orchards), and accounted for 5 to $71 \%$ of the total decay. Phacidiopycnis rot, gray mold caused by Botrytis cinerea, and blue mold caused by Penicillium spp. accounted for an average of $34.1,10.3$, and $33.6 \%$ of decayed fruit from conventional orchards, respectively; and $22.8,35.7$, and $23.5 \%$ of decayed fruit from organic orchards, respectively. During November 2001 to January 2002 (packing), Phacidiopycnis rot was observed in fruit that were stored in field bins before packing from 30 of 33 grower lots, accounting for $18.4 \%$ of decayed fruit sampled. During March to May in 2002, Phacidiopycnis rot was responsible for 2 to $68 \%$ of decayed fruit sampled from 36 of 39 grower lots. Phacidiopycnis rot, gray mold, and blue mold accounted for an average of 19.6, 26.8, and $37.4 \%$ of decayed fruit from conventional orchards, respectively; and 42.2, 25.7, and $8.2 \%$ of decayed fruit from organic orchards, respectively. Most Phacidiopycnis rot that occurred in field bins before packing appeared to originate from wound infections; whereas after packing, approximately 60 and 30\% of Phacidiopycnis rot originated from stem and calyx infections, respectively. This study indicates that Phacidiopycnis rot should be considered one of the targets for control of postharvest diseases in d'Anjou pears in the region.
\end{abstract}

Additional keywords: postharvest decay, Potebniamyces pyri

Winter pears in the United States are produced primarily in the Pacific Northwest. 'd'Anjou' (Pyrus communis L.) is one of the major winter pear varieties grown in the region. In Washington State, d'Anjou pear fruit are harvested in midSeptember. At harvest, fruit are placed into wooden or plastic field bins (approximately $400 \mathrm{~kg}$ of fruit per bin) and then transported into packinghouses. Fruit are initially stored in the field bins in ambient atmosphere or controlled atmosphere (CA) ( 1 to $2 \% \mathrm{O}_{2}$ and $0.5 \% \mathrm{CO}_{2}$ ) at -1 to $0^{\circ} \mathrm{C}$ (10) before packing. Packing starts shortly after harvest and may last until early January, depending on the volume of harvested fruit that needs to be packed. During packing, fruit with noticeable defects (wounds, limb rubs, poor size or shape, insect injury,

Corresponding author: C. L. Xiao

E-mail: clxiao@wsu.edu

Plant Pathology New Series 0370, Project 0367, College of Agriculture and Home Economics Research Center, Washington State University.

Accepted for publication 15 December 2003.

Publication no. D-2004-0210-01R

(C) 2004 The American Phytopathological Society decay, etc.) are removed from the packing line. Visually sound pears are individually wrapped in paper impregnated with copper sulfate, which is used to prevent the spread of decay during storage, packed into cardboard boxes ( $20 \mathrm{~kg}$ of fruit per box), and stored in CA at -1 to $0^{\circ} \mathrm{C}(10)$. Fruit can be stored in cardboard boxes for up to 9 months, during which time fruit rot may develop. Fruit packers have considered postharvest fruit rot to be the most serious problem for the long-term storage of winter pears in the Pacific Northwest (8). Under the current Washington State standard, only $2 \%$ decay incidence is allowed in a $20-\mathrm{kg}$ pear box at the time of shipping. Repacking to remove decayed fruit is often required in order to meet the standard, and the resulting direct and indirect losses (fruit decay, labor cost for repacking, etc.) cost millions of dollars a year to the pear industry in Washington State. Control of postharvest fruit decay is one of the essential components in a profitable production program for d'Anjou pears (8).

Several postharvest diseases commonly occur in d'Anjou pears in the U.S. Pacific Northwest $(11,13)$. In general, there are two groups of postharvest diseases in pome fruits: those that originate from incipient or quiescent fungal infections of fruit in the orchard and those that originate from infections of wounds, such as stem punctures and bruises, by fungi after harvest or during the handling and packing process (14). The former category is exemplified by Bull's-eye rot, caused by Neofabraea spp. (19), and gray mold calyx-end rot caused by Botrytis cinerea Pers.:Fr. (4). The latter category is exemplified by blue mold caused by Penicillium spp., primarily $P$. expansum Link, and Mucor rot caused by Mucor piriformis E. Fisch. $(14,20)$. The other form of fruit infection after harvest is fruit-to-fruit spread of decay in storage containers. $B$. cinerea is known to spread from decayed fruit to the surrounding sound fruit through fruit-to-fruit contact, sometimes causing a considerable amount of fruit decay (15). Understanding the origins of decay and the nature of its spread through secondary infection is essential for developing and implementing effective programs for control of postharvest diseases.

Phacidiopycnis rot, caused by $\mathrm{Pha}$ cidiopycnis piri (Fuckel) Weindlymayr, anamorph of the discomycete Potebniamyces pyri (Berkeley \& Broome) Dennis, is a newly recognized postharvest disease in pears in the United States (25). This disease has previously been reported only in Europe and India $(16,17)$, and research on it is sparse (17). Currently, there is no information available regarding the prevalence and relative importance of this disease in Washington State, one of the primary d'Anjou pear production areas in the United States. Information on the occurrence of Phacidiopycnis rot, as well as fruit rots caused by other decay-causing pathogens under the current production systems for d'Anjou pear, would help the pear industry implement effective measures to reduce storage losses resulting from postharvest diseases. The objectives of this study were to determine (i) the prevalence of Phacidiopycnis rot in stored d'Anjou pears, (ii) incidence of this disease as well as of fruit rots caused by other postharvest fungal pathogens in stored d'Anjou pears, and (iii) whether fruit-to-fruit spread of this disease occurs in CA storage.

\section{MATERIALS AND METHODS}

Packinghouse surveys. Surveys of Phacidiopycnis rot and other postharvest diseases in d'Anjou pears were conducted in the Wenatchee River Valley, the primary production area of d'Anjou pears in Wash- 
ington State. Surveys were conducted in four commercial packinghouses. One of the packinghouses packs only organic fruit. Because in Washington State d'Anjou pears are packed soon after harvest and stored in cardboard boxes in $\mathrm{CA}$ at -1 to $0^{\circ} \mathrm{C}$, the surveys were focused on postharvest diseases primarily in packed fruit that had been stored in cardboard boxes for a period of time after packing, which ranged from approximately 4 to 8 months. Because according to the Washington State standard, only $2 \%$ decay incidence is allowed in a $20-\mathrm{kg}$ pear box at the time of shipping, repacking (removing decayed fruit and transferring marketable fruit into new containers) may be needed in order to meet the standard. Some retailers may want pears in different size containers. Thus, repackaging (transferring fruit into different size containers as requested by buyers) may also be needed before shipping. In this study, decayed fruit were collected during repacking or repackaging operations during March to May in 2001 and 2002. Approximately 60 decayed fruit from each grower lot were randomly sampled from one or more cull bins or other containers (cardboard boxes or buckets) for culls (depending on how many cull bins or containers available for sampling) during repacking or repackaging operations. In this study, each grower lot represented a unique orchard. Twenty-six and 39 samples of decayed fruit were collected from individual grower lots during March to May in 2001 and 2002, respectively.

In addition, in order to determine whether or not Phacidiopycnis rot occurs in pear fruit stored in the field bins before packing, decayed fruit were sampled during the fruit packing operation in 2001 to 2002. In north-central Washington, d'Anjou pear packing starts shortly after harvest and usually ends in late December or early January. The survey was conducted from November 2001 to January 2002. Because packing of organic fruit usually ends before November, only conventional fruit were sampled. Approximately 60 decayed fruit from each grower lot were randomly collected from the cull bins during packing operations. Thirtythree samples, each representing fruit from one unique orchard (grower lot), were collected during November 2001 to January 2002.

Decayed fruit were transported to the laboratory on the same day they were collected from packinghouses. Decayed fruit were sorted by infection sites (stem-end, calyx-end, or fruit skin) and presence of wounds. Color and type of decay (soft or watery decay versus firm or spongy decay) also were recorded. When isolation was necessary, photos of decayed fruit were taken before isolation in order to correlate causal agents with the disease symptoms observed.
Isolation and identification of decaycausing agents. When sporulation or fruiting bodies of decay pathogens were present on decayed fruit, identification of causal agents was made based on the signs of pathogens or morphology of fungi under the microscope. When signs of pathogens were not present, decayed fruit were placed on foam fruit trays in plastic containers with moist paper towels on the bottom and kept at room temperature (20 to $22^{\circ} \mathrm{C}$ ) overnight to facilitate sporulation of fungi such as $B$. cinerea, Penicillium spp., and Mucor spp. If no positive signs of pathogens on decayed fruit were present after incubation, isolations of causal agents were made from decayed tissues as follows. Decayed fruit were sprayed with $70 \%$ ethanol and air-dried in a laminar hood. The skin of decayed fruit was peeled off with a sterile scalpel at the margin between decayed and healthy tissues. Then small fragments of the fruit flesh were excised and plated on acidified potato dextrose agar (APDA; Difco Laboratories, Detroit, MI) $(4.0 \mathrm{ml}$ of a $25 \%$ solution of lactic acid per liter of medium). Plates were incubated at room temperature (20 to $22^{\circ} \mathrm{C}$ ) and examined for culture development. When necessary, fungi that grew on or in the agar were transferred onto fresh APDA. Pure cultures were then transferred onto PDA or oatmeal agar (OMA; $60 \mathrm{~g}$ of iron- and zinc-fortified single-grain oatmeal [Gerber, Fremont, MI] with $15 \mathrm{~g}$ of agar in 1,000 ml of deionized water, sterilizing for $90 \mathrm{~min}$ ) and incubated at room temperature under $12-\mathrm{h}$ alternating cycles of dark and fluorescent light to induce sporulation of hyphomycetes or formation of fruiting bodies of coelomycetes. Identification of Phacidiopycnis piri was based upon the descriptions of the fungus by Potebnia (12) and DiCosmo et al. (5). On APDA, the fungus forms circular colonies with little or no aerial mycelia. Mycelia of the fungus initially appear light white to colorless, and later turn gray to dark, starting from the central part of colonies. On OMA at $20^{\circ} \mathrm{C}$ under 12 -h alternating cycles of dark and fluorescent light, conidia form in the pycnidia after 4 weeks of incubation. Conidia are hyaline, subglobose to obovoid, guttulate, 9-14 × 5.5-9 $\mu \mathrm{m}$ (5). Identification of other fungi was based on the descriptions by Barnett and Hunter (1), Carmichael et al. (2) (hyphomycetes), and Sutton (24) (coelomycetes).

Fruit-to-fruit spread of the disease during storage. d'Anjou pear fruit were harvested from a commercial orchard and a research orchard and used within 10 days for this experiment. In both orchards, no fungicides were applied at least 30 days before harvest, and fruit were also not treated with any postharvest fungicide. Fruit were surface-disinfested for $5 \mathrm{~min}$ in $0.5 \% \mathrm{NaOCl}$, rinsed three times with sterile water, and then air-dried. Pycnidia of $P$. piri produced on 8-week-old OMA cul- tures at $20^{\circ} \mathrm{C}$ under 12 -h alternating cycles of dark and fluorescent light were used to make conidial suspensions for fruit inoculation. Concentrations of the spore suspensions were adjusted to $1 \times 10^{4}$ conidia per $\mathrm{ml}$. Pieces of sterile $2 \times 2 \mathrm{~cm}$ cheesecloth were dipped into the spore suspensions. Fruit were wounded with a sterile 4-mmdiameter nail head to a depth of $4 \mathrm{~mm}$ and then inoculated by covering wounds with a piece of wet cheesecloth containing spore suspensions of the fungus. Inoculated fruit were kept overnight in muffin trays in plastic moist chambers at room temperature $\left(20\right.$ to $\left.22^{\circ} \mathrm{C}\right)$. After incubation, the cheesecloth was then removed from the inoculated fruit, and fruit were laid in the bottom of a cardboard pear box. The box was divided horizontally into three sections, one for each replicate. Nonwounded fruit were laid in a single layer on top of the inoculated fruit. Each of three replicates had 7 to 10 inoculated fruit in the bottom and 7 to 10 sound fruit on the top. Fruit were then stored in $\mathrm{CA}\left(1.5 \% \mathrm{O}_{2}\right.$ and $\left.0.5 \% \mathrm{CO}_{2}\right)$ at $0^{\circ} \mathrm{C}$. Fruit-to-fruit spread of Phacidiopycnis rot was examined monthly for 5 months, starting 2 months after inoculation. At the end of the experiment, five decayed fruit originating from fruit-tofruit spread were selected for reisolation of the fungus. The experiment was conducted twice, using fruit from a different orchard each time.

\section{RESULTS}

2000 to 2001 storage season. In addition to gray mold and blue mold, which were commonly found in packed d'Anjou pears stored in cardboard boxes, Phacidiopycnis rot was an important component of storage fruit rots in d'Anjou pears. Phacidiopycnis rot was observed in packed fruit from 22 of 26 grower lots sampled during March to May 2001. Phacidiopycnis rot, gray mold, blue mold, and Mucor rot accounted for an average of $34.1,10.3,33.6$, and $19.3 \%$ of the decayed fruit that came from conventional orchards, respectively, and 22.3, 35.7, 23.5, and $1.4 \%$ of decayed fruit that came from organic orchards, respectively (Table 1). Bull's-eye rot accounted for $7.4 \%$ of the decayed fruit from organic orchards and $0.8 \%$ from conventional orchards (Table 1). Other minor postharvest diseases included Alternaria rot caused by Alternaria spp., Aureobasidium rot caused by A. pullulans, Cladosporium rot caused by $C$. herbarum, and those associated with unidentified fungi and yeasts.

Percentages of Phacidiopycnis rot, gray mold, and blue mold in the total decayed fruit within a grower lot varied among lots sampled (Fig. 1A). Phacidiopycnis rot comprised more than $20 \%$ of the decayed fruit in $62 \%$ of the lots sampled, and accounted for more than $50 \%$ of the decayed fruit in $31 \%$ of the lots. Gray mold and blue mold accounted for more than $20 \%$ of 
the decayed fruit in 27 and $65 \%$ of the lots, respectively. About $42 \%$ of the lots had gray mold, accounting for 1 to $10 \%$ of the total decayed fruit; whereas $12 \%$ of the lots had blue mold, accounting for 1 to $10 \%$ of the total decayed fruit.

P. piri was associated with three types of symptoms in d'Anjou pears: stem-end rot, calyx-end rot, and wound-associated rot. Among the fruit with Phacidiopycnis rot, the vast majority exhibited stem-end rot. During March to May 2001, approximately 89, 10, and $1 \%$ of Phacidiopycnis rot originated from infections at the stem, calyx, or wounds on the fruit skin, respectively (Fig. 2A).

2001 to 2002 storage season. Decay before packing. During November 2001 to January 2002, gray mold and Phacidiopycnis rot were the two predominant diseases in fruit stored in the field bins before packing, accounting for 59.7 and $18.4 \%$ of the decayed fruit, respectively, whereas blue mold accounted for $12 \%$ of the decayed fruit (Table 2). Mucor rot was not commonly found in fruit stored in the field bins. Bull's-eye rot was first observed in January, after about 3.5 months of storage. Sphaeropsis rot, a newly reported postharvest disease caused by Sphaeropsis pyriputrescens (27), occurred in fruit from 14 of 33 orchards during the early storage period before packing. Sphaeropsis rot accounted for 2 to $8 \%$ of the total decayed fruit. Other minor decays included Alternaria rot, sprinkler rot caused by $P h y$ tophthora cactorum (Lebert \& Cohn) Schroter, Cladosporium rot, Aureobasidium rot, and those associated with unidentified fungi and yeasts. The vast majority of decays that occurred in fruit stored in the field bins originated from fungal infections at physical wounds.

Phacidiopycnis rot was observed in fruit from 30 of 33 grower lots sampled from November 2001 to January 2002. Phacidiopycnis stem- and calyx-end rots accounted for 27 and $19 \%$ of the total Phacidiopycnis rot during that period, whereas approximately 54\% of the Phacidiopycnis rot apparently originated from wound infections (Fig. 2B). In November, all Phacidiopycnis rot observed had apparently originated from wound infections. Stem- and calyx-end infections caused by $P$. piri were first observed in early December, but initially accounted for only a small proportion in the total Phacidiopycnis rot sam- pled during that period. By early January (the end of the packing season in northcentral Washington State and after 3 months of CA storage), more Pha-

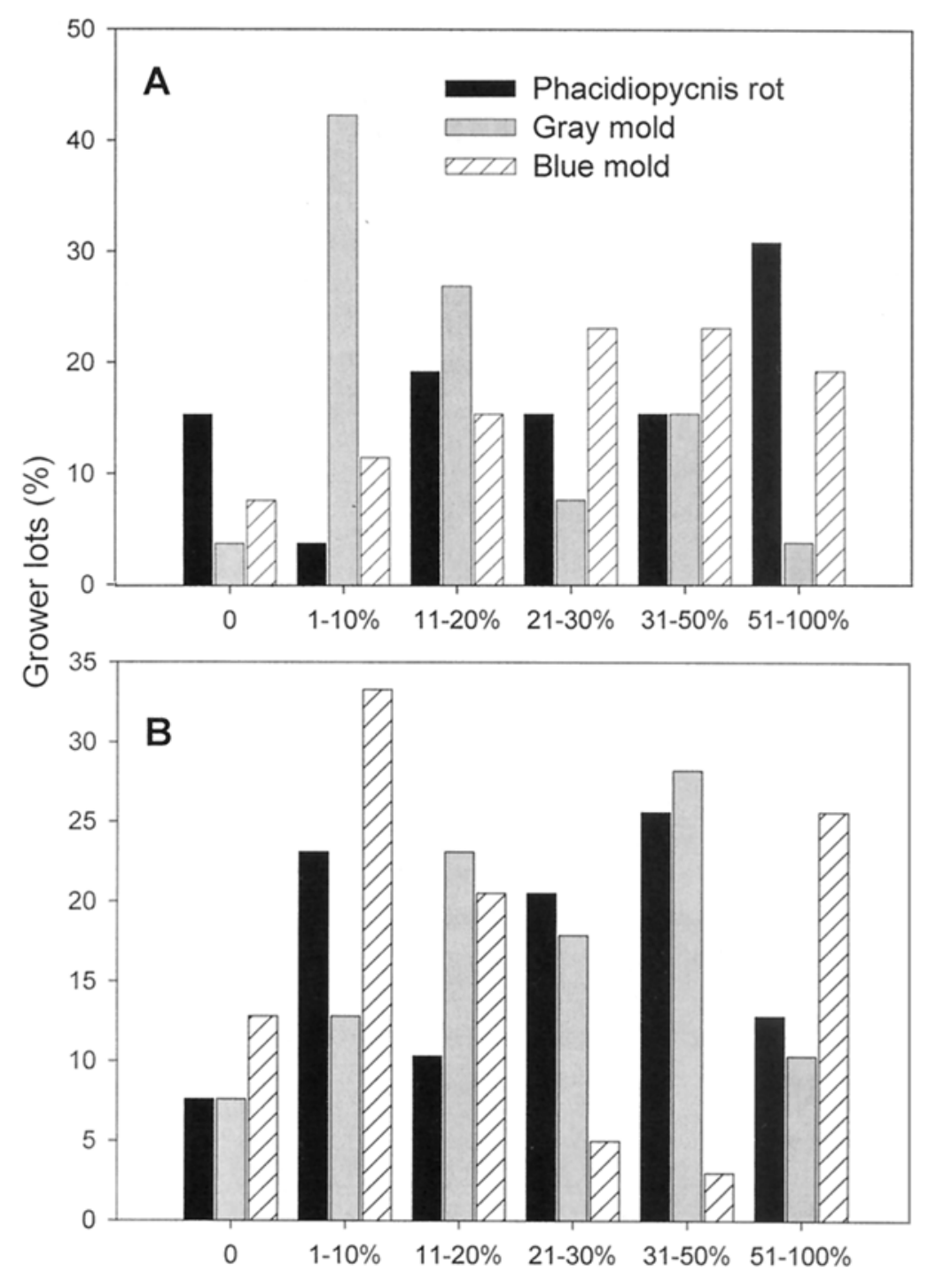

Percentage of the total decayed fruit within a grower lot

Fig. 1. Percentage of grower lots with different levels of Phacidiopycnis rot caused by Phacidiopycnis piri, gray mold caused by Botrytis cinerea, and blue mold caused by Penicillium spp. expressed as percentages in the total decayed d'Anjou pears within a grower lot collected during March to May in A, 2001 and B, 2002. Twenty-six and 39 samples of approximately 60 decayed fruit each were collected in 2001 and 2002, respectively. Each sample represents the fruit from one unique orchard.

Table 1. Mean percentages of postharvest fruit rots caused by different pathogens in the total decayed pear fruit sampled from March to May in 2001 and $2002^{\mathrm{a}}$

\begin{tabular}{|c|c|c|c|c|c|c|c|c|}
\hline Year & $\begin{array}{l}\text { Production } \\
\text { system }\end{array}$ & $\begin{array}{l}\text { Phacidiopycnis } \\
\text { rot }\end{array}$ & Gray mold & Blue mold & Mucor rot & Bull's-eye rot ${ }^{b}$ & $\begin{array}{l}\text { Sphaeropsis } \\
\text { rot }\end{array}$ & Others $^{\mathrm{c}}$ \\
\hline \multirow[t]{2}{*}{2001} & Conventional & 34.1 & 10.3 & 33.6 & 19.3 & 0.8 & $\mathrm{ND}^{\mathrm{d}}$ & 1.8 \\
\hline & Organic & 22.8 & 35.7 & 23.5 & 1.4 & 7.4 & ND & 9.2 \\
\hline \multirow[t]{2}{*}{2002} & Conventional & 19.6 & 26.8 & 37.4 & 8.1 & 2.2 & 2.0 & 3.8 \\
\hline & Organic & 42.2 & 25.7 & 8.2 & 0.5 & 7.4 & 4.5 & 11.5 \\
\hline
\end{tabular}

${ }^{a}$ Pears were stored in cardboard boxes after packing. Samples were collected when repacking or repackaging was in operation. In 2001,26 samples $(6$ organic and 20 conventional) of approximately 60 decayed fruit each were collected. In 2002, 39 samples (13 organic and 26 conventional) of approximately 60 decayed fruit each were collected. Each sample represents the fruit from one unique orchard.

${ }^{\mathrm{b}}$ Bull's-eye rot is caused by Neofabraea spp.

${ }^{\mathrm{c}}$ Include Alternaria rot, Aureobasidium rot, Cladosporium rot, and other minor fruit rots caused by unidentified fungi and yeasts.

${ }^{\mathrm{d}} \mathrm{ND}=$ not determined. 
cidiopycnis rot was observed as stem and calyx infections (Fig. 2B).

Decay after packing. In packed fruit sampled during March to May 2002, Phacidiopycnis rot, gray mold, blue mold, and Mucor rot accounted for an average of $19.6,26.8,37.4$, and $8.1 \%$ of the decayed fruit from conventional orchards, respectively, and $42.2,25.7,8.2$, and $0.5 \%$ of the decayed fruit from organic orchards, re- spectively. Bull's-eye rot accounted for 2.2 and $7.4 \%$ of the decayed fruit from conventional and organic orchards, respectively (Table 1). Sphaeropsis rot occurred in 19 of 39 grower lots, accounting for 2 to $21 \%$ of the total decayed fruit. Other minor postharvest diseases included Alternaria rot, Aureobasidium rot, Cladosporium rot, and those associated with unidentified fungi and yeasts.

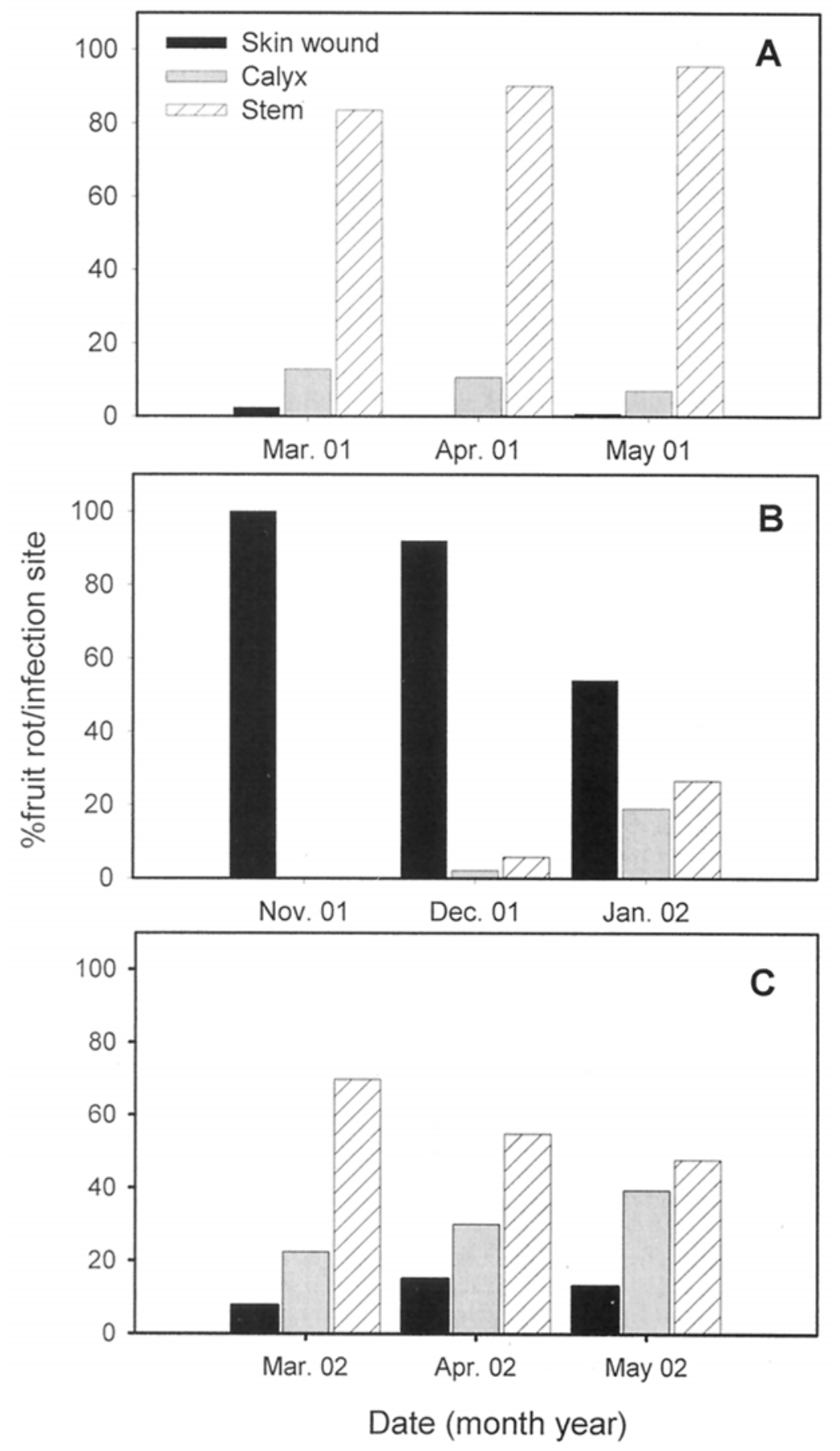

Fig. 2. Percentage of Phacidiopycnis rot originating from infections at stem, calyx, and skin wound sites by Phacidiopycnis piri in d'Anjou pears sampled during A, March to May in 2001, B, November 2001 to January 2002, and C, March to May in 2002. Seven, 14, and 5 samples of approximately 60 decayed fruit each were collected in March, April, and May 2001, respectively; 10, 13, and 10 samples of approximately 60 decayed fruit each were collected in November and December 2001, and January 2002, respectively; and 9, 18, and 12 samples of approximately 60 decayed fruit each were collected in March, April, and May 2002, respectively. Each sample represents fruit from one unique orchard.

Phacidiopycnis rot was prevalent and observed in packed fruit from 36 of 39 grower lots sampled during March to May 2002. Percentage of decay caused by various pathogens varied from lot to lot (Fig. 1B). Approximately $46 \%$ of the lots had Phacidiopycnis rot accounting for 21 to $50 \%$ of the total decay, but $23 \%$ of the lots had a low level of Phacidiopycnis rot, ranging from 1 to $10 \%$ in the total decayed fruit. The percentage of blue mold in the total decayed fruit varied greatly from lot to lot. About $33 \%$ of the lots had blue mold ranging from 1 to $10 \%$ in the total decayed fruit; only $8 \%$ of the lots had blue mold ranging from 21 to $50 \%$ in the total decayed fruit; but $26 \%$ of the lots had more than $50 \%$ of the decayed fruit caused by Penicillium spp. The percentage of gray mold in the total decayed fruit within a lot also varied among the lots (Fig. 1B).

During March to May 2002, approximately 60 and $30 \%$ of the observed Phacidiopycnis rot appeared to originate from stem and calyx infections, respectively (Fig. 2C).

Fruit-to-fruit spread during storage. Two months after inoculation, all inoculated fruit developed Phacidiopycnis rot symptoms, and mycelia of the fungus formed on the surface of decayed areas, whereas about $7 \%$ of the nonwounded, sound fruit that were laid on top of the inoculated fruit developed Phacidiopycnis rot symptoms (Fig. 3). After 3 months in CA storage at $0^{\circ} \mathrm{C}$, over $50 \%$ of the sound fruit developed Phacidiopycnis rot symptoms due to fruit-to-fruit contact with inoculated fruit. Five months after the initiation of the experiment, all sound fruit laid on top of the inoculated fruit developed Phacidiopycnis rot due to contact with the inoculated fruit (Fig. 3). No decay symptoms started at sites on the fruit surfaces other than at the contact point with inoculated fruit. $P$. piri was reisolated from decayed fruit.

\section{DISCUSSION}

In this study, we documented that Phacidiopycnis rot was an important component of postharvest decays in d'Anjou pears in north-central Washington. Over the 2-year disease survey, Phacidiopycnis rot occurred in approximately $90 \%$ of the sampled grower lots and accounted for an average of $30 \%$ of the decayed fruit during the storage period from March to May. The information presented in this study may have implications for management of postharvest diseases in d'Anjou pears in the region. The survey results indicate that in addition to gray mold and blue mold, Phacidiopycnis rot should also be considered one of the target diseases in a program for control of postharvest diseases in d'Anjou pears in north-central Washington State. In this study, actual loss due to decay in each grower lot was not determined. The surveys were primarily focused on the de- 
cayed fruit. However, the vast majority of samples of decayed fruit were collected from grower lots when repacking was needed. Thus, in most grower lots sampled, at least an average of $2 \%$ decay incidence in packed fruit was anticipated. Since the initial discovery of $P$. piri in Washington State, the fungus has been found to be widespread in the pear production areas of the U.S. Pacific Northwest (26). The relative importance of this disease in other pear production areas in the region remains to be determined.

Previously, only the stem-end rot phase of Phacidiopycnis rot was observed in Europe $(7,17)$. In the present study, we documented that in addition to stem-end rot, $P$. piri can also be associated, although less frequently, with calyx-end rot of d'Anjou pear fruit in storage, and that it apparently invaded wounds on fruit skin and later developed into decay. It is unknown when infections of the stem and calyx of fruit occur in the orchard. Different types of symptoms may originate from different infection mechanisms by the pathogen. For example, calyx-end rot may originate from systemic infection of flowers and immature fruit by the pathogen during the pear growing season, like gray mold calyx-end rot in pears. $B$. cinerea enters filaments, spreads into the receptacle or mesocarp at any time between pear bloom and harvest, then becomes latent in these tissues, and later develops into decay in storage (4). Defining the etiology and ecology of three phases of Phacidiopycnis rot in d'Anjou pears would help us understand the timing of fruit infection by the fungus and further develop a disease management program to control this disease.

After harvest, all harvested fruit, including those with various defects, such as insect damage, bruises, and stem punctures that occur during the harvesting and handling process, are stored in the field bins. During packing from November to January, gray mold and Phacidiopycnis rot were predominant among the decays observed in the field bins (Table 2). The vast majority of fruit decay observed in field bins appeared to originate from wound infections by $B$. cinerea (data not shown) and P. piri (Fig. 2B). This indicates that if pears are harvested and stored in the field bins for several months, decay control should target gray mold, Phacidiopycnis rot, and blue mold-particularly the first two diseases, because they can spread through fruit-to-fruit contact during storage. This is particularly important in postharvest handling systems in which fruit are stored in the field bins for several months until packing. This handling system is common in the mid-Columbia region of Oregon, the other major d'Anjou pear production area in the United States (9).

During the 2-year survey, percentage of Phacidiopycnis rot in the total decayed fruit within a grower lot varied among the lots sampled (Fig. 1). There was no consistent difference in Phacidiopycnis rot between organic and conventional fruit (Table 1). In eastern Washington State, because of the semiarid climate, fungal diseases in pear orchards are of much less concern than in pear production regions with frequent rain and humid conditions during the pear-growing season. Even in the conventional production system, rela- tively few fungicide sprays (0 to 2 ) are applied. Therefore, fungicides in conventional orchards may have limited effects on fruit infection by $P$. piri, in comparison with the organic production system. Postharvest handling and packing practices for conventional and organic fruit are different. At packing, for conventionally grown pears, sodium $o$-phenylphenate or chlorine is commonly used to reduce populations of decay-causing fungi in the dump tank or flume water $(21,22)$. Thiabendazole is commonly applied through a line sprayer on the packing line for decay control. For organically grown fruit, synthetic fungicides are not allowed, and only chlorine or chlorine dioxide is used. Both conventional and organic fruit are commonly treated with commercialized biocontrol agents, such as Aspire (Candida oleophila; Ecogen, Langhorne, PA) or Bio-Save 110 (Pseudomonas syringae; EcoScience, Worcester, MA), on the packing line. These chemical and biocontrol products have been reported to reduce decay originating from infection of wounds by vari-

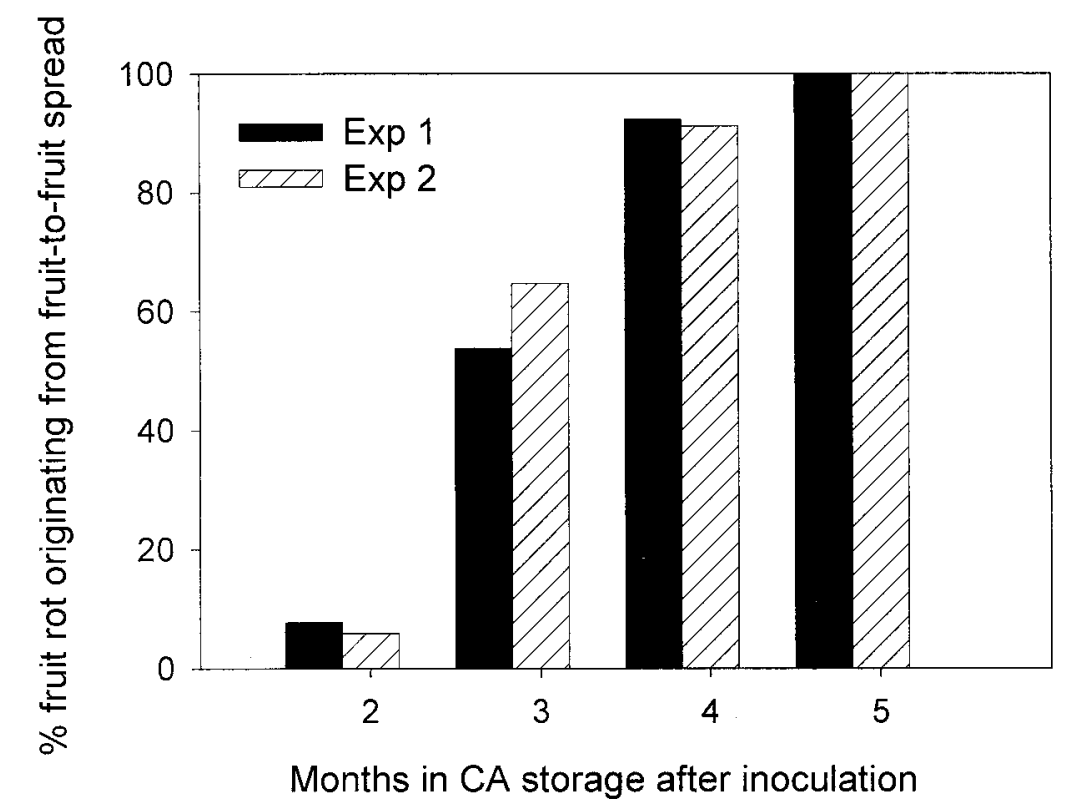

Fig. 3. In laboratory experiments, percentage of fruit showing Phacidiopycnis rot symptoms apparently originating from fruit-to-fruit contact in controlled atmosphere (CA) storage at $0^{\circ} \mathrm{C}$. Sound fruit were laid on top of fruit that were wound-inoculated with the pathogen.

Table 2. Mean percentages of postharvest fruit rots caused by different pathogens in the total decayed fruit sampled from mid-November 2001 to early January 2002

\begin{tabular}{|c|c|c|c|c|c|c|c|c|c|}
\hline $\begin{array}{l}\text { Sampling } \\
\text { period }^{\mathrm{a}}\end{array}$ & $\begin{array}{l}\text { Phacidiopycnis } \\
\text { rot }\end{array}$ & Gray mold & Blue mold & Mucor rot & $\begin{array}{l}\text { Bull's-eye } \\
\text { rot }^{\text {b }}\end{array}$ & $\begin{array}{l}\text { Sprinkler } \\
\operatorname{rot}^{c}\end{array}$ & $\begin{array}{l}\text { Alternaria } \\
\text { rot }\end{array}$ & $\begin{array}{l}\text { Sphaeropsis } \\
\text { rot }\end{array}$ & Others $^{\mathrm{d}}$ \\
\hline November & 11.7 & 51.9 & 20.4 & 1.0 & 0 & 0.2 & 4.5 & 0 & 10.3 \\
\hline December & 24.9 & 63.3 & 4.9 & 0.1 & 0 & 2.4 & 0.4 & 1.9 & 2.1 \\
\hline January & 18.5 & 63.9 & 10.7 & 0 & 1.0 & 0.8 & 1.0 & 2.3 & 1.8 \\
\hline Mean & 18.4 & 59.7 & 12.0 & 0.4 & 0.3 & 1.1 & 1.7 & 1.4 & 5.0 \\
\hline
\end{tabular}

${ }^{a}$ Pears were stored in the field bins before packing. Samples were collected when packing was in operation. Ten, 13 , and 10 samples of approximately 60 decayed fruit each were collected in November and December 2001, and January 2002, respectively. Each sample represents the fruit from one unique orchard.

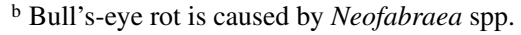

c Sprinkler rot is caused by Phytophthora cactorum.

${ }^{\mathrm{d}}$ Include Cladosporium rot, Aureobasidium rot, and minor fruit rots caused by unidentified fungi and yeasts. 
ous decay-causing pathogens (23). It is unknown whether these postharvest practices are effective in controlling Phacidiopycnis rot. Currently, research is underway to evaluate effectiveness of postharvest fungicide practices in controlling Phacidiopycnis rot.

Incidence of decays caused by other pathogens also varied considerably among lots sampled. In 2002, $25 \%$ of the sampled lots had $>50 \%$ of the decay caused by Penicillium spp., but about $35 \%$ of the lots had $<10 \%$ of the decay caused by Penicillium spp. (Fig. 1). The higher percentage of Mucor rot in conventional fruit in 2001 also resulted from a few lots with very high level of the disease (data not shown). This incidence pattern is likely associated with variation in populations of pathogens in the dump tank water during the packing process, because spores of Mucor and Penicillium in the dump tank or flume water are the major source of inoculum for fruit infections (18).

We also documented that $P$. piri has the ability to spread from decayed fruit to surrounding, sound fruit in experiments under commercial storage conditions, but Phacidiopycnis rot resulting from fruit-tofruit spread among packed, paper-wrapped fruit in cardboard boxes was not commonly seen during the survey. In the northcentral Washington pear industry, pears are individually wrapped at packing with paper impregnated with copper sulfate to prevent the spread of decay $(3,6)$. This practice may also minimize the potential spread of Phacidiopycnis rot among packed fruit under the current handling system. However, we observed that fruitto-fruit spread of Phacidiopycnis rot occurred in nonwrapped fruit under commercial storage conditions (C. L. Xiao and R. J. Boal, personal observation). Our data indicate that gray mold and Phacidiopycnis rot, apparently originating from wound infection, were predominant among decays observed in the field bins. Thus, it is important to reduce the amount of gray mold and Phacidiopycnis rot in the field bins in order to prevent losses due to secondary fruit infections through fruit-to-fruit spread. Fruit-to-fruit spread of decay should be considered one important factor when fruit are harvested and stored in the field bins (in which pears are not wrapped with paper) for several months before packing.

\section{ACKNOWLEDGMENTS}

We thank R. G. Roberts for the identification of Phacidiopycnis piri; J. Betz, P. Burnett, D. Gaspar, B. Gix, L. Kutch, L. Moser, R. Spanjer, and E. Strutzel for assistance in sampling; D. Corey for technical assistance; and R. G. Roberts and J. W. Sitton for helpful comments on the manuscript. This research was supported in part by the Winter Pear Control Committee.

\section{LITERATURE CITED}

1. Barnett, H. L., and Hunter, B. B. 1998. Illustrated Genera of Imperfect Fungi. 4th ed. American Phytopathological Society, St. Paul, MN.

2. Carmichael, J. W., Kendrick, W. B., Conners, I. L., and Sigler, L. 1980. Genera of Hyphomycetes. University of Alberta, Edmonton, Alberta, Canada.

3. Cooley, J. S., and Crenshaw, J. H. 1931. Control of Botrytis rot of pears with chemically treated wrappers. U.S. Dep. Agric. Circ. 177.

4. De Kock, S. L., and Holz, G. 1992. Blossomend rot of pears: Systemic infection of flowers and immature fruit by Botrytis cinerea. J. Phytopathol. 135:317-327.

5. DiCosmo, F., Nag Raj, T. R., and Kendrick, W. B. 1984. A revision of the Phacidiaceae and related anamorphs. Mycotaxon 21:1-234.

6. Drake, S. R., Elfving, D. C., and Gix, R. D. 2001. The influence of paper wraps on the quality of 'd'Anjou' pears after controlled atmosphere storage. HortTechnology 11:566570.

7. Govi, G. 1952. Un marciume di frutti immagazzinati (Phacidiopycnis furfuracea (Rostr.) Jorst.). Ann. Sper. Agrar. (NS) 6:11211129 .

8. Kupferman, E. A. 1995. Practices to reduce postharvest pear diseases. Tree Fruit Postharvest J. 6:18-23.

9. Kupferman, E. A. 1998. Postharvest chemicals applied to pears: A survey of pear packers in Washington, Oregon, and California. Tree Fruit Postharvest J. 9:3-24.

10. Meheriuk, M. 1993. CA storage conditions for apples, pears, and nashi. Pages 819-841 in: Proc. Int. Controlled Atmosphere Res. Conf., 6th. Cornell University, Ithaca, NY.

11. Pierson, C. F., Ceponis, M. J., and McColloch, L. P. 1971. Market diseases of apples, pears, and quinces. U.S. Dep. Agric. Agric. Handb. 376.

12. Potebnia, A. 1912. Ein neuer Krebserreger des
Apfelbaumes Phacidiella discolor (Mout. Et Sacc.) A. Pot., seine Morphologie und Entwickelungsgeschichte. Z. Pflanzenkrank. 22:129-153.

13. Pscheidt, J. W., and Ocamb, C. M., eds. 2003. Pacific Northwest Plant Disease Management Handbook. Oregon State University, Corvallis.

14. Rosenberger, D. A. 1990. Postharvest diseases. Pages 53-54 in: Compendium of Apple and Pear Diseases. A. L. Jones and H. S. Aldwinckle, eds. American Phytopathological Society, St. Paul, MN.

15. Rosenberger, D. A. 1990. Gray mold. Pages 55-56 in: Compendium of Apple and Pear Diseases. A. L. Jones and H. S. Aldwinckle, eds. American Phytopathological Society, St. Paul, MN.

16. Sharma, R. L. 1991. Prevalence of storage rots of China pear in Himachal Pradesh. Plant Dis. Res. 5:109-111.

17. Snowdon, A. L. 1992. Post-harvest Diseases and Disorders of Fruits and Vegetables, Vol. 1 General Introduction and Fruits. CRC Press, Boca Raton, FL.

18. Spotts, R. A. 1986. Relationships between inoculum concentrations of three decay fungi and pear fruit decay. Plant Dis. 70:386-389.

19. Spotts, R. A. 1990. Bull's-eye rot. Pages 56 in: Compendium of Apple and Pear Diseases. A L. Jones and H. S. Aldwinckle, eds. American Phytopathological Society, St. Paul, MN.

20. Spotts, R. A. 1990 . Mucor rot. Pages 57-58 in: Compendium of Apple and Pear Diseases. A. L. Jones and H. S. Aldwinckle, eds. American Phytopathological Society, St. Paul, MN

21. Spotts, R. A., and Cervantes, L. A. 1989 Evaluation of disinfestant-flotation saltsurfactant combinations on decay fungi of pear in a model dump tank. Phytopathology 79:121-126.

22. Spotts, R. A., and Peters, B. B. 1980. Chlorine and chlorine dioxide for control of d'Anjou pear decay. Plant Dis. 64:1095-1097.

23. Sugar, D., and Spotts, R. A. 1999. Control of postharvest decay in pear by four laboratorygrown yeasts and two registered biocontrol products. Plant Dis. 83:155-158.

24. Sutton, B. C. 1980. The coelomycetes. Commonwealth Mycological Institute, Kew, England.

25. Xiao, C. L., and Boal, R. J. 2002. Pathogenicity and infection courts of Phacidiopycnis piri in pears. (Abstr.) Phytopathology 92:S88.

26. Xiao, C. L., and Boal, R. J. 2003. Distribution of Potebniamyces pyri in the Pacific Northwest and its association with bark necrosis and canker on twigs of pear trees. (Abstr.) Phytopathology 93:S92.

27. Xiao, C. L., and Rogers, J. D. 2004. A postharvest fruit rot in d'Anjou pears caused by Sphaeropsis pyriputrescens sp. nov. Plant Dis. 88:114-118. 